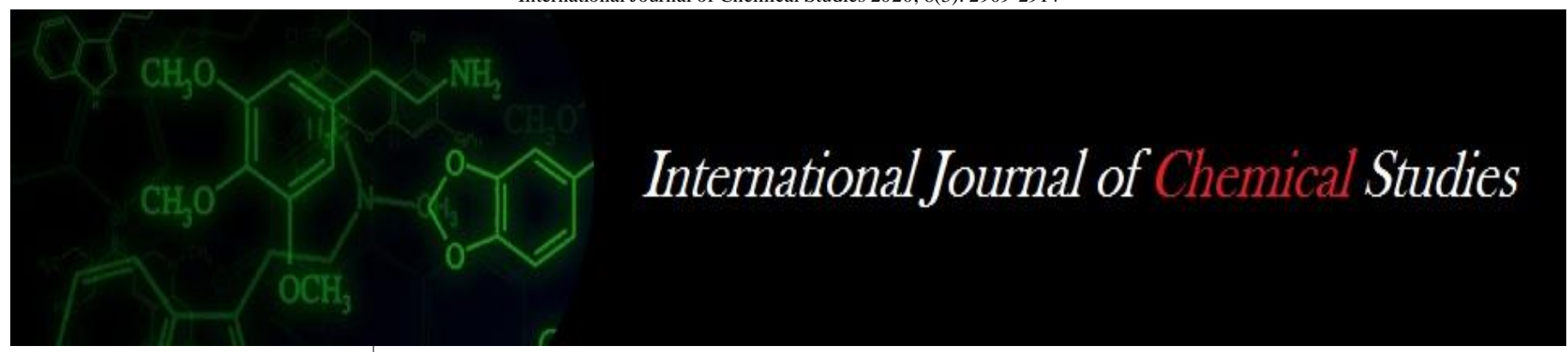

P-ISSN: 2349-8528

E-ISSN: 2321-4902

www.chemijournal.com

IJCS 2020; 8(3): 2909-2914

(C) 2020 IJCS

Received: 24-03-2020

Accepted: 28-04-2020

Rishi Richa

Assistant Professor, College of Agricultural Engineering and

Technology, Sher-e- Kashmir University of Agricultural Sciences and Technology, Shalimar, Srinagar, Jammu and Kashmir, India

JP Pandey

Professor Department of Post-Harvest Process and Food Engineering, College of Technology, G. B. Pant University of Agriculture and Technology, Pantnagar, Distt. US Nagar, Uttarakhand, India

NC Shahi

Professor Department of Post-Harvest Process and Food Engineering, College of Technology, G. B. Pant University of Agriculture and Technology, Pantnagar, Distt. US Nagar, Uttarakhand, India

UC Lohani

Professor Department of Post-Harvest Process and Food Engineering, College of Technology, G. B. Pant University of Agriculture and Technology, Pantnagar, Distt. US Nagar, Uttarakhand, India

Yogesh Pandey

Assistant Professor, College of

ngineering and

Technology, Sher-e- Kashmir University

of Agricultural Sciences and Technology,

Shalimar, Srinagar, Jammu and

Kashmir, India.

RM Shukla

Assistant Professor, College of Agricultural Engineering and Technology, Sher-e- Kashmir University of Agricultural Sciences and Technology,

Shalimar, Srinagar, Jammu and Kashmir, India.

B Langoo

Assistant Professor, College of Agricultural Engineering and Technology, Sher-e- Kashmir University of Agricultural Sciences and Technology, Shalimar, Srinagar, Jammu and Kashmir, India.
Corresponding Author: Rishi Richa

Assistant Professor, College of Agricultural Engineering and Technology, Sher-e- Kashmir University of Agricultural Sciences and Technology, Shalimar, Srinagar, Jammu and Kashmir, India.

\section{Study of microbial load for storage and optimization conditions of Malta (Citrus Sinensis) using response surface methodology}

\author{
Rishi Richa, JP Pandey, NC Shahi, UC Lohani, Yogesh Pandey, RM \\ Shukla and B Langoo
}

DOI: https://doi.org/10.22271/chemi.2020.v8.i3ap.9655

\begin{abstract}
Response surface methodology (RSM) was used to determine the optimum storage conditions of malta fruits that gives minimum microbial load or growth and maximum shelf life retained value. Scavenger (3-5 g), polythene thickness (75-125 gauge) and fungicide concentration (75-200 ppm) were the factors investigated. Experiments were designed according to Box-Behnken design with these three factors, including central points. For each response, a second-order polynomial model was developed using multiple linear regression analysis. Applying desirability function method, optimum storage conditions were found to be $5 \mathrm{~g}$ scavenger, 125-gauge polythene thickness and $200 \mathrm{ppm}$ fungicide concentration. All the parameters significantly affect the response. It is observed that all factors are suitable to reduce the microbial load which is helpful for extending the shelf life of malta fruits up to four months at ambient condition. Box Benkhen can be successfully applied for modeling and optimizing the storage parameters. Applying desirability function method, optimum storage conditions were found to be $5 \mathrm{~g}$ scavenger, 125-gauge polythene thickness and 200 ppm fungicide concentration.
\end{abstract}

Keywords: Box-Behnken, RSM, storage of malta, microbial load and shelf life

\section{Introduction}

Malta or Sweet orange (Citrus sinensis) is a member of the citrus family (Snart 2006) ${ }^{[12]}$. Citrus spp. consists of group of fruits belonging to the Rutaceae family. Malta is having high acceptability due to its attractive color, distinctive flavor and taste. The major medicinal properties of orange include anti-bacterial, anti-fungal, anti- diabetic, cardio- protective, anticancer, anti-arthritic, anti-inflammatory, anti-oxidant, anti-Tubercular, anti-asthmatic and antihypertensive (Parle and Chatuevedi; 2012) ${ }^{[8]}$. However, malta is available for only one or two months, therefore it cannot be stored for longer period under ambient conditions and cannot be transported to distant places due to its short shelf life. Citrus fruits are non-climacteric in nature and their eating quality cannot be improved after harvest, so care should be taken at the optimum harvesting time period. Enhancement of shelf-life of malta become necessary for the purpose of increasing the local raw materials, decreasing the post-harvest losses and for using the processed product out of season (Dasmohapatra et al., 2011) ${ }^{[1]}$ and all these factors affect the national economy as well as state which will be beneficial for farmers also. In order to store malta fruits active packaging (consists of scavenger such as $\mathrm{KMnO}_{4}$ and activated charcoal) was used prior to fungicide treatment. In view of this, active packaging for storage of malta was investigated. During the storage the formation of $\mathrm{CO}_{2}$ is enhanced due to respiration reactions, and more and more the ethylene is produced from packaged fruits and vegetables. Accumulated gases produced during the storage time, have to be removed from the package to avoid the food deterioration and the packaging destruction so there should be provision of a system which can remove these gases and for this purpose scavenger is a good option (Floros, 1997) ${ }^{[2]}$. Moreover, the development of these activities will make it possible to increase the value of local raw materials; decrease post-harvest losses and to use processed products out of season. It is also helpful in increasing farmers' income; and integrates family-type rural farming into the market economy as it is a method to store the commodity at ambient 
condition as no cold storage, extra energy and electricity required for this method (Richa et al. 2016) ${ }^{[11]}$.

Three effective factors; scavenger amount, polythene thickness, and fungicide concentration were used for enhancement of shelf life of malta. The statistical method using response surface methodology (RSM) has been proposed to determine the influences of individual factors and the influence of their interactions. RSM has been reported to be an effective tool for optimization of a process when the independent variables have a combined effect on the desired response. RSM is a collection of statistical and mathematical system that has been successfully used for developing, improving and optimizing such processes (Koocheki et al. 2009) ${ }^{[5]}$. It is a technique to design experiments, build models, evaluate the effects of several factors, and to attain the optimum conditions for desirable responses with a limited number of planned experiments. RSM helps to demonstrate how input variables over some specified region of interest affects particular response and what independent variables will yield a maximum (or minimum) for a specific response (Khuri and Cornell, 1996) ${ }^{[4]}$. The response surface design was used in this study: 1) to find how microbial count comprising of several levels of shelf life factors can be simplified, 2) to determine how microbial count and shelf life (as responses) are affected by changes in the level of storage parameters, 3) to determine the optimum combination of storage parameters that yields the best storage life. These objectives were quantitatively measured by RSM for optimization of microbial count, shelf life and color

\section{Materials and methods}

Fresh malta fruits were used for storage study. The fresh malta was procured from the market of Almora district, Uttarakhand; the storage study was conducted for 4 months in the lab. Fruits were dipped in azoxystrobin fungicide solution for $1 \mathrm{~min}$ to resist fungus attack and after that fruits were kept under ambient conditions at least 5-6 h so that the moisture of fungicide solution get evaporated from malta surface and fruit become safe for storage i.e. microorganism could not attack on malta due to absence of moisture. Digital balance was used for weighing the treated malta fruits and then two malta fruits were kept in one box. On the base of box, decided amount of scavenger $\left(\mathrm{KMnO}_{4}\right.$ and activated charcoal) was kept in petri dish. Boxes were packed with polythene bag of different thickness (permeability) and stored at room temperature for further analysis for microbial load and shelf life as per method prescribed (Ranganna, 2005) ${ }^{[9]}$. All the treated samples were kept for four months storage. For storage of malta, mill board boxes $(18.5 \times 15 \times 10 \mathrm{~cm})$ were used. Each box has base in which six perforations were made and each side face has two perforations for the exchange of gases so that accumulation of gases does not take place and fresh air was maintained inside the box to prevent the an aerobic condition inside the box.

\subsection{Experimental design}

Independent variables should satisfy important assumptions which are as fallows

- Variables should be measurable,

- Variables should be continuous and

- Variables should be controllable by experiments, with negligible errors,

The RSM course of action was carried out as follows (Trinh and Kang, 2010) ${ }^{[13]}$ :
1. For sufficient and dependable measurement of the response of interest a series of experiments were performed

2. The second-order response surface mathematical model with the best fit was developed.

3. The optimum response value was determined.

RSM was used as it helps to reduce the number of experiments without affecting the accuracy of results and to decide interactive effects of variables on the response. BoxBehnken designs are response surface designs especially made to require only 3 levels, coded as $-1,0$, and 1 . BoxBehnken designs may consist of 3 to 21 factors. They are formed by combining two levels factorial design with incomplete block design (Khuri and Cornell, 1996) ${ }^{[4]}$.

Box- Behnken design, which is a very efficient design tool for fitting second-order models, was selected for use in this study. Based on literatures and preliminary experiments conducted the level chosen for scavenger $\left(\mathrm{X}_{1}\right)$, polythene thickness $\left(\mathrm{X}_{2}\right)$ and fungicide $\left(X_{3}\right)$ for enhancing the shelf life of malta under ambient condition. After defining the desired value ranges of the independent variables, they were coded as \pm 1 as the factorial points, 0 as the center points. The ranges of variables as in coded and actual form for the design of experiments are shown in Table 1.

Table 1: Levels of independent variables in coded and actual form for storage study of malta fruits

\begin{tabular}{|c|c|c|c|c|c|}
\hline \multicolumn{2}{|c|}{ Independent variables } & \multicolumn{4}{|c|}{ Coded Levels } \\
\hline \multirow{2}{*}{ Name } & \multirow{2}{*}{ Code } & -1 & 0 & +1 \\
\cline { 3 - 5 } & & \multicolumn{3}{|c|}{ Actual Levels } \\
\hline Scavenger (g) & $\mathrm{X}_{1}$ & 3 & 4 & 5 \\
\hline Polythene thickness (gauge) & $\mathrm{X}_{2}$ & 75 & 100 & 125 \\
\hline Fungicide concentration (ppm) & $\mathrm{X}_{3}$ & 100 & 150 & 200 \\
\hline
\end{tabular}

*coded and actual values used in response surface methodology for experiment design

\subsection{Measurements of quality parameters}

\subsubsection{Microbial count of Malta during storage}

After the preparation of samples, microbial load in fermenting liquor evaluated by pour plating method.

\subsection{1(a) Preparation of serial dilution series}

One $\mathrm{ml}$ of malta juice sample was withdrawn from each flask and diluted into nine $\mathrm{ml}$ of distilled water, which was $10^{-1}$ dilution. In the same way, dilution series up to $10^{-9}$ dilution levels were prepared.

One $\mathrm{ml}$ sample from $10^{-3}$ to $10^{-9}$ dilution level was inoculated into three different petri plates and PDA media was poured over the samples and mixed thoroughly by rotating clockwise and anticlockwise several times. The plates were set in duplicates. All plates were incubated at $30{ }^{\circ} \mathrm{C}$. After three days, the number of colonies on each plate were observed, counted and expressed as CFU/ml of Malta juice

\subsection{1(b) Total viable counts in Malta.}

Each petri plate was divided into four equal parts and then the colonies were counted in a single part and then multiplied by 4 , this gives the total number of colonies in a single Petri plate. (Ranganna, 2005) ${ }^{[9]}$.

$$
\text { Colony forming unit }(\mathrm{CFU})=\frac{\text { No of colonies } \times \text { Dilution Factor }}{\text { Aliquot sample }}
$$


A complete second mathematical model (Equation 2) model was fitted to the data and the adequacy of the model was tested considering the coefficient of multiple determinations $\left(\mathrm{R}^{2}\right)$, Fisher's F-test and lack of fit (LOF). The models were then used to interpret the effect of various parameters on the response. Optimization of process parameters was carried out at the end of the analysis. The optimized values of process parameters were used in storage and contours were developed for selected parameters.

The second order mathematical response function for three independent variables has the following form:

$$
Y=\beta_{0}+\sum_{i=1}^{3} \beta_{i} X_{i}+\sum_{i=1}^{2} \sum_{j=i+1}^{3} \beta_{i j} X_{i} X_{j}+\sum_{i=1}^{3} \beta_{i i} X_{i}^{2}
$$

Or

$\mathrm{Y}=\beta_{0}+\beta_{1} \mathrm{X}_{1}+\beta_{2} \mathrm{X}_{2}+\beta_{3} \mathrm{X}_{3}+\beta_{12} \mathrm{X}_{1} \mathrm{X}_{2}+\beta_{1} 3 \mathrm{X}_{1} \mathrm{X}_{3}+\beta_{23} \mathrm{X}_{2} \mathrm{X}_{3}+\beta_{11} \mathrm{X}_{1}{ }^{2}+\beta_{22} \mathrm{X}_{2}{ }^{2+} \beta_{33} \mathrm{X}_{3}{ }_{3}$

where,

$\beta_{0}, \beta_{\mathrm{i}}, \beta_{\mathrm{ii}}, \beta_{\mathrm{ij}}$ are coefficient of regression (coefficients of regression of linear, interaction and quadratic terms, respectively)

$\mathrm{X}_{\mathrm{i}}, \mathrm{X}_{\mathrm{j}}$ are independent variables (where, $\mathrm{i}=1,2$, and $\mathrm{j}=1,2 \ldots$ ) $\mathrm{Y}$ is the predicted response (microbial count or load and shelf life) used as a dependent variable

$x_{\mathrm{i}}(i=1,2)$ the input predictors or controlling variables (factors)

Multiple linear regression analysis was used for determining the coefficient parameters by employing the software DesignExpert (version 8). Design-Expert was also used to find the 2$\mathrm{D}$ contour plots of the response models. The value of $\mathrm{p}$ in the model represented the probability of significance. Model analysis, lack-of-fit test and $\mathrm{R}^{2}$ (coefficient of determination) analysis is used to check the adequacies of the models (Lee $e t$ al. 2000 and Weng et al. 2001) ${ }^{[6,14]}$. The lack-of fit evaluates the failure of a model to represent data in the experimental domain at which points were not included in the regression and variations in the models cannot be accounted by random error (Montgomery 1984) ${ }^{[7]}$. Coefficient of variation (CV) indicates the relative dispersion of the experimental points from the model prediction.

\section{Results and discussion}

\subsection{Model fitting}

Seventeen observed response values observed were used to compute the mathematical model using the least square method. The two dependent variables as microbial count and shelf life were correlated with the three factors (scavenger amount, polythene thickness and fungicide concentration), using the second-order polynomial, as represented by Eqn 2 . After fitting experimental data, quadratic regression models were developed, as shown in Eqn (4) and (5).

$\mathrm{CFU}$ or microbial count $(\mathrm{Y})=6.6 \times 10^{5}-2.37 \times 10^{4} \mathrm{X}_{1}-$ $3.37 \times 10^{4} \mathrm{X}_{2}-1.45 \times 10^{5} \mathrm{X}_{3}-1.75 \times 10^{4} \mathrm{X}_{1} \mathrm{X}_{2}-2.0 \times 10^{4} \mathrm{X}_{1} \mathrm{X}_{3}+$ $1.0 \times 10^{4} \mathrm{X}_{2} \mathrm{X}_{3}+4.82 \times 10^{4} \mathrm{X}_{1}^{2}-2.67 \times 10^{4} \mathrm{X}_{2}^{2}+4.57 \times 10^{4} \mathrm{X}_{3}^{2}$ (4)

Where,

$\mathrm{Y}=$ Colony forming unit $(\mathrm{CFU} / \mathrm{ml}) /$ microbial count

Shelf life $(\mathrm{Y})=102.00+8.75 \mathrm{X}_{1}+13.75 \mathrm{X}_{2}+0.000 \mathrm{X}_{3}+7.50$ $\mathrm{X}_{1} \mathrm{X}_{2}+0.000 \mathrm{X}_{1} \mathrm{X}_{3}+0.000 \mathrm{X}_{2} \mathrm{X}_{3}-2.25 \mathrm{X}_{1}^{2}-7.25 \mathrm{X}_{2}^{2}+0.25 \mathrm{X}_{3}^{2}$

(5)

$\mathrm{Y}=$ shelf life (days)
Where, $\mathrm{X}_{1}, \mathrm{X}_{2}$ and $\mathrm{X}_{3}$ are the amount of scavenger, thickness of polythene and concentration of fungicide. The coefficients with one factor (the ones in front of $\mathrm{X}_{1}$ or $\mathrm{X}_{2}$ or $\mathrm{X}_{3}$ ) represent the effects of the certain factor, while the two factors coefficients (the ones in front of $\mathrm{X}_{1} \mathrm{X}_{2}$ or $\mathrm{X}_{1} \mathrm{X}_{3}$ or $\mathrm{X}_{2} \mathrm{X}_{3}$ ) and quadratic terms (the ones in front of $\mathrm{X}_{1}{ }^{2}$ or $\mathrm{X}_{2}{ }^{2}$ or $\mathrm{X}_{3}^{2}$ ) represent the interaction between the two factors and the effect of quadratic term respectively. The synergistic effect was shown by positive sign effect, while the negative sign indicates an antagonistic effect.

It is noted that coefficients with $\mathrm{p}$ value $<0.01$ are those with significant effects toward the microbial load and shelf life, thus those variables with $p>0.01$ can be omitted from the regression. Moreover, under the assumption of the insignificant effect of interaction, the variables $\mathrm{X}_{2}^{2}, \mathrm{X}_{1}$ and, $X_{3}$, respectively are neglected for microbial count and $X_{2} X_{3}$, $\mathrm{X}_{1} \mathrm{X}_{3}$ and quadratic term of $\mathrm{X}_{1}$ and $\mathrm{X}_{3}$ are neglected for shelf life. Furthermore, it is observed that variable $\mathrm{X}_{3}$ fungicide addition play important role to stop the growth off fungus. Therefore, equation with significant term can be written as fallows-

CFU or Microbial count $(\mathrm{Y})=6.6 \times 10^{5}-3.37 \times 10^{4} \mathrm{X}_{2}-$ $1.45 \times 10^{5} \mathrm{X}_{3}+4.82 \times 10^{4} \mathrm{X}_{1}^{2+} 4.57 \times 10^{4} \mathrm{X}_{3}^{2}$

\section{$\mathrm{R}^{2}=97.99 \%$ and Adj R-Squared $=95.40 \%$}

Equation (6): Microbial count will increase by decreasing the value of scavenger; polythene thickness and fungicide concentration. The effect of polythene thickness (3.37) is the highest and as compare to amount of scavenger (2.37).

Shelf life $(\mathrm{Y})=102.00+8.75 \mathrm{X}_{1}+13.75 \mathrm{X}_{2}+7.50 \mathrm{X}_{1} \mathrm{X}_{2}-7.25$ $\mathrm{X}_{2}{ }^{2}$

$\mathrm{R}^{2}=96.12 \%$ and Adj R-Squared $=91.13 \%$

Equation (7): There will be an increase in shelf life with increase of all three parameters. The polythene thickness has got more effect on shelf life will the value of 13.75 while a scavenger has less effect as compare to polythene thickness 8.75 .

\subsection{Validation of the Models}

The developed quadratic model is usually used to examine for ensuring it provides an adequate approximation to the actual system. When model shows an adequate fit, then proceeding with an investigation and optimization of the fitted response surface is likely to give good or real results. Graphical techniques, graphical and numerical methods were used as a primary tool and confirmation to validate the models (Trinh and Kang, 2010) ${ }^{[13]}$.

The developed models were then checked using a numerical method employing the coefficient of determination $\left(\mathrm{R}^{2}\right)$, adjusted $R^{2}\left(R^{2}\right.$ adj), and then calculated as shown in Equation (8) and (9) (Haber and Runyun, 1977) ${ }^{[3]}$, the coefficient of determination $\mathrm{R}^{2}$ indicates how much of the observed variability in the data was accounted for by the model, while by taking into account the number of covariates or predictors in the model $\mathrm{R}^{2}$ adj modifies $\mathrm{R}^{2}$. 


$$
\begin{aligned}
& R^{2}=1-\frac{S S_{\text {Re sidual }}}{S S_{\text {Model }}+S S_{\text {Residial }}} \\
& R^{2}{ }_{\text {Adj }}=1-\frac{n-1}{n-p}\left(1-R^{2}\right)
\end{aligned}
$$

Where, SS is the sum of the squares, $n$ experiments number, and $p$ the number of predictors (term) in the model, not counting the constant term. Experimental data were used to develop the quadratic model in this study with the values of $\mathrm{R}^{2}$ higher than $90 \%$, say $97.99 \%$ and $96.12 \%$ of microbial load and shelf life of stored Malta, respectively. Furthermore, an $\mathrm{R}_{\text {adj }}^{2}$ very close to the $R^{2}$ values for the response microbial load than the shelf life ensures a satisfactory adjustment of the quadratic models to the experimental data and having least residual error in the model. Therefore, the regression models explained to check the effect of each response on independent variables well.

\subsection{Microbial count (Colony Forming Unit (CFU)) and shelf life}

Colony Forming Unit (CFU) increases as storage time is increased and as the substrate is being utilized it becomes constant. During storage CFU ranged from 5.0E+4 to $9.0 \mathrm{E}+4$ during the course of storage. Maximum cell count was observed for experiment no. 5 ( $3 \mathrm{~g}$ scavenger level, 100 gauge polythene packaging and $100 \mathrm{ppm}$ azoxystrobin fungicide) of storage while minimum was at experiment no. 12 at $(4 \mathrm{~g}$ scavenger, 100 gauge polythene and $200 \mathrm{ppm}$ azoxystrobin fungicide concentration). The microbial counts or load did not exceed the acceptable limits in the treatments; however, higher counts were observed at the end of storage.

ANOVA on microbial count model, as shown in Table 2, demonstrates that the models were highly significant $(p<0.01)$. A model $\mathrm{F}$ value 4.12 implies that the model is significant. The Fisher F-test with a very low probability value $(\mathrm{P}$ model_ $\geq \mathrm{F}$ at 0.01$)$ demonstrates a very high significance for the regression model. The determination coefficient $\left(\mathrm{R}^{2}\right)$ checks the goodness of- fit of the model. The coefficient of determination $\left(\mathrm{R}^{2}\right)$ was $97.99 \%$ for microbial count. The lack of fit F-value of 1.34 indicates the lack of fit is not significant relative to the pure error. There is a $38.05 \%$ chance that a lack of fit F-value this large could occur due to noise. Non-significant lack of fit indicates good fit model. The Pred $\mathrm{R}^{2}$ of $82.31 \%$ is in reasonable agreement with the Adj $\mathrm{R}^{2}$ of $95.40 \%$. The signal- to- noise ratio is measured by Adequate precision (Adeq precision) whose desirable value is 4. Noise ratio of 20.781 indicates an adequate signal.

The shelf life ranged for the storage from 80 to 120 days. Maximally all the treated Malta fruit showing 80days storage life. The maximum shelf life was observed for Expt. 4 (5g of scavenger $\left(5 \mathrm{~g} \mathrm{KMnO}_{4}+5 \mathrm{~g}\right.$ of activated charcoal), 125 gauge thick polythene wrap and $150 \mathrm{ppm}$ of fungicide whose shelf life was 120 days while minimum range of shelf life was observed at Expt. ( $3 \mathrm{~g}$ of scavenger $\left(3 \mathrm{~g} \mathrm{KMnO}_{4}+3 \mathrm{~g}\right.$ of activated charcoal), $150 \mathrm{ppm}$ of azoxystrobin fungicide $\left(\mathrm{X}_{3}=\right.$ 0 ) and 75 gauge thickness polythene wrap. Ethylene scavenger reduce the Ethylene content which is a main ripening inducing agent of fruits may cause the premature ripening of some products, even ruin others. Beside this packaging material maintain accumulation of $\mathrm{CO}_{2}$, restricted intake of $\mathrm{O}_{2}$ from atmosphere, low level of relative humidity of the air in the storage space, and the lower rate of respiration of fruits. Therefore, these combinations could help to enhance the shelf life. This finding is similar to Reddy et al., $2008^{[10]}$.

ANOVA on shelf life model, as shown in Table 2, demonstrates that the models were highly significant $(p<0.01)$. A model $\mathrm{F}$ value 19.26 implies that the model is significant. The Fisher F-test with a very low probability value ( $\mathrm{P}$ model $\_\mathrm{F}$ at 0.01$)$ demonstrates a very high significance for the regression model. The determination coefficient $\left(\mathrm{R}^{2}\right)$ checks the goodness of- fit of the model. The coefficient of determination $\left(\mathrm{R}^{2}\right)$ was $96.12 \%$ for shelf life. The lack of fit F-value of 0.42 indicates the lack of fit is not significant relative to the pure error. There is a $75.10 \%$ chance that a "Lack of Fit F-value" this large could occur due to noise. The Pred $\mathrm{R}^{2}$ of $80.60 \%$ is in reasonable agreement with the Adj $\mathrm{R}^{2}$ of $91.13 \%$. The signal- to- noise ratio is measured by Adequate precision (Adeq precision) whose desirable value is 4 . Noise ratio of 15.149 indicates an adequate signal.

The model was found to be adequate and the best fit equation were developed in order to draw contour plots for showing the effect of independent variables on those responses and to select the range of variables for an acceptable Malta storage condition. Lines or curves of constant response values are drawn on a plane or graph whose coordinate axes represent the levels of independent variables and the response is visualized perpendicular to the plane of paper. Series of contour lines of equal response value were generated which provided useful information for understanding the effect of two independent parameters on the dependent variable.

Table 2: Total effect of individual parameter on microbial count for stored Malta

\begin{tabular}{|c|c|c|c|c|c|}
\hline & & \multicolumn{2}{|c|}{ Microbial count } & \multicolumn{2}{c|}{ Shelf life } \\
\hline Source & DF & MS & F-Value & MS & F-Value \\
\hline Model & 9 & $2.55 \mathrm{E}+9$ & $4.12 * *$ & 288.98 & $19.26 * * *$ \\
\hline Scavenger $\left(\mathrm{X}_{1}\right)$ & 4 & $4.0 \mathrm{E}+10$ & $65.96 * * *$ & 214.705 & $14.31 * * *$ \\
\hline Polythene thickness $\left(\mathrm{X}_{2}\right)$ & 4 & $3.25 \mathrm{E}+9$ & $5.35 * *$ & 489.705 & $32.647 * * *$ \\
\hline Fungicide conc ${ }^{\mathrm{n}}\left(\mathrm{X}_{3}\right)$ & 4 & $4.47 \mathrm{E}+10$ & $73.71 * * *$ & 0.065 & 0.00433 \\
\hline Linear & 3 & $6.03 \mathrm{E}+10$ & $99.43 * * *$ & 708.33 & $47.22 * * *$ \\
\hline Quadratic & 3 & $7.2 \mathrm{E}+9$ & $11.87 * * *$ & 80.96 & $5.3 * *$ \\
\hline Interactive & 3 & $1.06 \mathrm{E}+9$ & 1.748 & 75 & $5 * *$ \\
\hline \multicolumn{7}{|c|}{ Error } & 7 & $6.05 \mathrm{E}+8$ & & 15 & \\
\hline Total & 16 & & & & \\
\hline$* * *, * *$ Significant at 1 and 5\% level of significance respectively
\end{tabular}

\subsection{Coding of the variables was done as per the following 3.4.1 Storage}

The independent variables were coded as $\mathrm{X}_{1}, \mathrm{X}_{2}$ and $\mathrm{X}_{3}$ for scavenger, polythene and fungicide as per given below, respectively.

$$
\begin{gathered}
\mathrm{X}=\frac{\text { Independent variable }- \text { central value }}{\text { Interval gap }} \\
\mathrm{X}_{1}=\frac{\text { Scavenger }-4}{1} \\
\mathrm{X}_{2}=\frac{\text { Polythene }-100}{25} \\
\mathrm{X}_{3}=\frac{\text { Fungicide }-150}{50}
\end{gathered}
$$




\subsection{Numerical optimization of process parameters for of malta}

Optimization is a process of making compromises between responses, to achieve a common target. Numerical optimization was carried out using Design-Expert 8.0.6 statistical software and carried out to predict the optimum storage condition of malta fruits within selected ranges which generated the desired response goal. The desired goals for each factor and response were chosen and different weights were assigned to each goal. The responses namely microbial load and shelf life, were taken into consideration for optimization. The goal seeking begins at random starting points and proceeds up and down the steepest slope on the response surface for a maximum and minimum value of the response respectively. Importance to the responses and independent variables were given on the basis of objectives of the study. Maximum importance (++++) was given to the minimum to microbial count and maximize the shelf life.

Optimization of processing conditions was carried out to keep the scavenger and fungicide in range and shelf life retained. Based on mentioned criteria, the optimization was carried out. During optimization, 17 solutions were obtained in case of storage of malta, out of which the one that suited the criteria most was selected. The goal setup for optimization of shelf life of malta and the constrains are given in Table 3.

Table 3: Constraints and optimum values of process parameters and responses for optimization of stored malta

\begin{tabular}{|c|c|c|c|}
\hline Names & Goal & Lower limit & Upper limit \\
\hline Scavenger amount & Is in range & -1 & +1 \\
\hline Polythene thickness & Maximize & -1 & +1 \\
\hline Fungicide Concentration & Is in range & -1 & +1 \\
\hline Microbial count & Minimize & 5000 & 9000 \\
\hline Shelf life & Maximize & 80 & 120 \\
\hline
\end{tabular}

The optimum solution was emerged out as storage condition is $5 \mathrm{~g}$ scavenger ( $5 \mathrm{~g} \mathrm{KMnO}_{4}$ and $5 \mathrm{~g}$ activated charcoal), 125 gauge polythene thickness and $200 \mathrm{ppm}$ fungicide which is optimized condition for enhancing the shelf life of malta fruit to retain its quality, in order to obtain optimized storage as microbial load and shelf life. Fig 1 shows contour plot for microbial load as a function of scavenger and fungicide at optimum point which depicts microbial count increases by decreasing the value of polythene thickness and fungicide concentration while Fig 2 shows contour plot for shelf life as a function of scavenger with polythene thickness at optimum point. Shelf- life of malta fruit increases with increase in scavenger amount and polythene thickness.

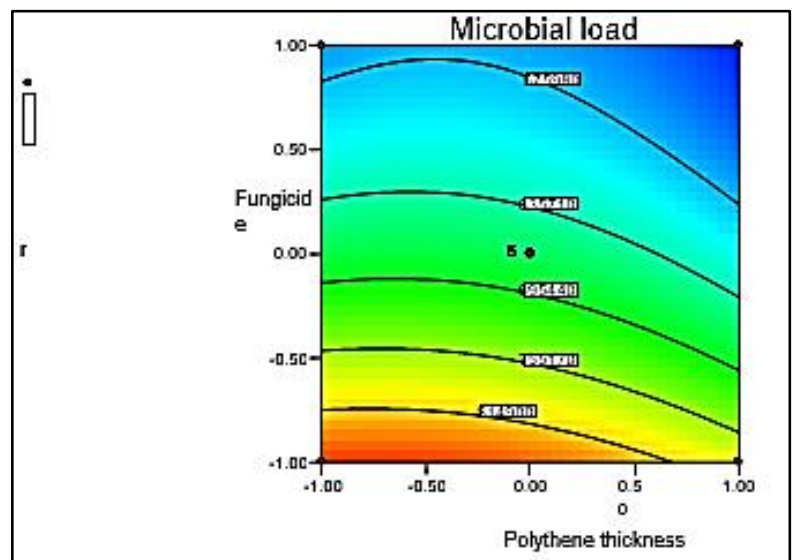

Fig 1: Contour plot for microbial load as a function of scavenger and fungicide at optimum point

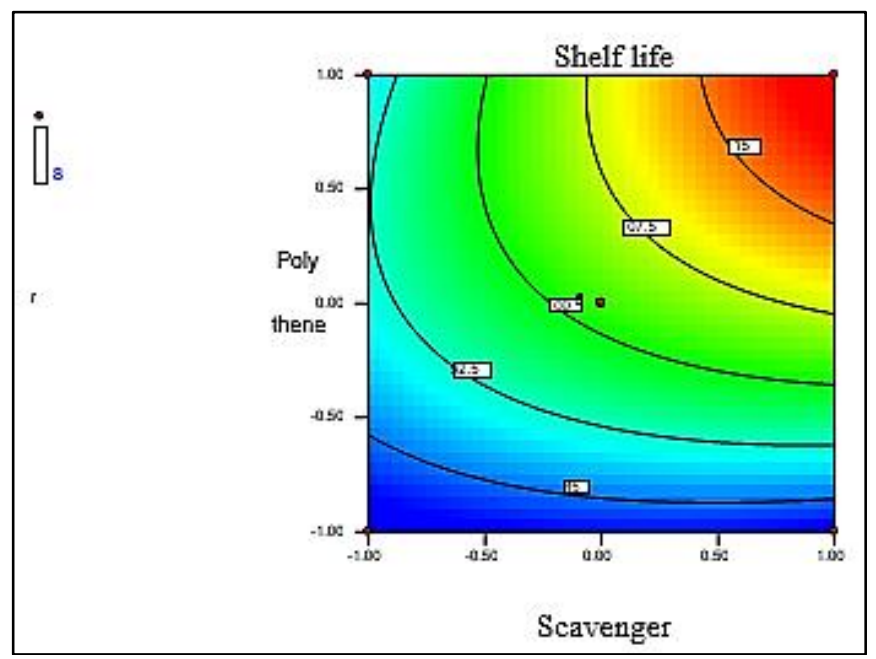

Fig 2: Contour plot for shelf life as a function of scavenger with polythene thickness at optimum point

\section{Conclusion}

RSM was effectively used to determine the effect of scavenger, polythene thickness and fungicide during storage of malta fruits. A total of 17 combinations of these independent variables were formed to see the effect on different dependent variables microbial count and shelf life. On the basis of experiment studies and data analysis it can be concluded that microbial count and shelf life could be maintained by using scavenger, polythene and fungicide. The optimum condition is reached by using $5 \mathrm{~g}$ scavenger $(5 \mathrm{~g}$ $\mathrm{KMnO}_{4}$ and $5 \mathrm{~g}$ activated charcoal), 125 gauge polythene thickness and $200 \mathrm{ppm}$ of fungicide concentration to get minimum microbial load while maintaining maximum shelf life by experimental and analytical data. The results of a confirmation experiments were found to be in good agreements with the values predicted by model. It demonstrates that to get maximum amount of information, in a short period with the least number of experiments, Box Benkhen can be successfully applied for modeling and optimizing the storage parameters.

\section{Acknowledgements}

This research was carried out in the department of Post Harvest Process \& Food Engineering and funded by the Indian Council of Agriculture Research under All India coordinated research project on Post Harvest Technology. We sincerely thanks to Head, PHPFE, Director Research and Dean, College of Technology, G.B.P.U.A. \& T., Pantnagar for providing necessary requirements for smooth conducting of the research work.

\section{References}

1. Dasmohapatra R, Nautiyal MC, Sharma SK. Effect of pedicel retention and zero energy cool chamber on storage behavior of malta fruits. International Journal of Agriculture Sciences. 2011; 3(2):78-81.

2. Floros JD, Dock LL, Han JH () Active Packaging Technologies and Applications. Food Cosmetics and Drug Packaging X: 10, 1997.

3. Haber A, Runyun RP. General statistics. 3rd ed. Reading, MA: Addision-Wesley, 1977.

4. Khuri AL, Cornell JA (). Responses Surfaces: design and analysis. 2nd ed. New York, Marcel Dekker, 1996, 114116

5. Koochek A, Taherian AR, Razavi SMA, Bostan A () Response surface methodology for optimization of 
extraction yield, viscosity, hue and emulsion stability of mucilage extracted from Lepidium perfoliatum seeds. Food Hydrocolloids. 2009; 23:2369-2379

6. Lee J, Ye L, Landen WO, Eitenmiller RR. Optimization of an extraction procedure for the quantification of vitamin $\mathrm{E}$ in tomato and broccoli using response surface methodology. Journal of Food Composition Anal. 2000; 13:45-57.

7. Montgomery DC () Design and analysis of experiments, 2nd ed. New York: John Wiley and Sons, 1984.

8. Parle, M, Chaturvedi D. Orange: Range of Benefit. International Research Journal of Pharmacy. 2012; 3(7):59-63

9. Ranganna S. Handbook of analysis and quality control for fruit and vegetables. Tata McGraw Hill Pub. Co. Ltd., New Delhi, 2005, 87.

10. Reddy VB, Madhavi GB, Reddy DV, Reddy VC, Srinu B. Effect of different packing materials on the shelf life and quality of acid lime (citrus aurantifolia swingla.) at room temperature. Journal of Dairying, Foods \& H.S. 2008; 27(3/4):216-220.

11. Rishi Richa, Pandey JP, Shahi NC, Kautkar SS. Optimization of storage conditions of malta (citrus sinensis) using response surface methodology. DOI 10.1515/ijfe-2015-0231

12. Snart, JE, Arpaia, ML, Harris LJ. Oranges: Safe methods to store preserve and enjoy. University of California. Division of Agriculture and Natural Resources. ANR Publication, 2006, 8199. http://anrcatalog.ucdavis.edu.

13. Trinh TK, Kang LS. Application of response surface method as an experimental design to optimize coagulation test. Environmental Engineering Research, 2012; 15(2):063-070

14. Weng W, Liu W, Lin W. Studies on the optimum models of the dairy product Kou Woan Lao using response surface methodology. Asian-Australas Journal of Animal Science. 2001; 14:1470-6. 